\title{
A rare clinical finding of mandibular distomolar at Aminu Kano Teaching Hospital
}

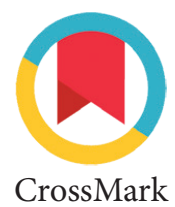

\author{
Babatunde O. Bamgbose, ${ }^{1,2^{*}}$ Zahrau S. Abdu, ${ }^{1}$ Olajumoke Enahoro, ${ }^{1}$ George \\ Ewansiha, ${ }^{1}$ Anas I. Yahaya, ${ }^{3}$ Edugie Ekuase, ${ }^{4}$ Auwal S. Balarabe, ${ }^{5}$ Junichi Asaumi, ${ }^{2}$
}

\section{Abstract}

Objective: Supernumerary teeth, also called fourth molar, in the mandibular molar region is a rare clinical finding. The reported prevalence of supernumerary teeth is $1.5-3.5 \%$ in the permanent dentition and $0.3-0.6 \%$ in the deciduous dentition. The supernumerary molars can be divided into two types: distomolars and paramolars.

Material and Methods: A 23-year-old female patient presented with symptoms of pericoronitis associated with an unerupted mandibular third molar at the Oral Diagnosis Clinic of the Aminu
Kano Teaching Hospital. Periapical radiograph revealed an incidental finding of mandibular distomolar in the region of the left unerupted mandibular third molar.

Results: This paper reports an unusual case of mandibular distomolar, incidence and prevalence, etiologic factors and management of mandibular distomolars.

Conclusion: Distomolars are a rare clinical finding and are often impacted and located in the maxilla.
${ }^{1}$ Oral Diagnostic Sciences Department, Faculty of Dentistry, Bayero University Kano, Kano

${ }^{2}$ Department of Oral and Maxillofacial Radiology, Okayama University Graduate School of Medicine, Dentistry and Pharmaceutical Sciences, Okayama

${ }^{3}$ Department of Anatomy, Faculty of Basic Medical Sciences, Bayero University Kano, Kano

${ }^{4}$ Department of Chemistry and Forensic Sciences, Savannah State University, Georgia

${ }^{5}$ Department of Child Dental Health, Faculty of Dentistry, Bayero University Kano, Kano

*Correspondence to: Babatunde 0 . Bamgbose, Oral Diagnostic Sciences Department, Faculty of Dentistry, Bayero University Kano, Kano

drtundebamgbose@yahoo.com

Received: 19 February 2019

Revised: 25 February 2019

Accepted: 20 March 2019

Available Online 1 August 2019

Keywords: Distomolar, Rudimentary tooth, Supplemental tooth

Cite this Article: Bamgbose BO, Abdu ZS, Enahoro 0, Ewansiha G, Yahya Al, Ekuase E, Balarabe AS, Asaumi J. 2019. A rare clinical finding of mandibular distomolar at Aminu Kano Teaching Hospital. Journal of Dentomaxillofacial Science 4(2): 117-119. D0l:10.15562/ jdmfs.v4i2.878

\section{Introduction}

Distomolars ("fourth molar") are supernumerary teeth distal to the third molar and are often detected by chance finding on routine radiographic examination. Though distomolars are generally asymptomatic they may be associated with several complications. ${ }^{1-3}$ They are frequently more common in the maxillary arch in both genders, though opinions vary in the literature regarding sex prevalence. ${ }^{2,4}$ Shahzad and Roth reported the percentage of fourth molar to be slightly higher in male $(2.2 \%)$, notably more common in blacks $(6.4 \%)$ than in white $(0.9 \%)$ and often show no significant laterality. ${ }^{4}$

A supernumerary tooth is one that is in excess of the usual configuration of the deciduous or permanent dentition. ${ }^{5,6}$ It arises from hyperactivity of the tooth germ in a single or multiple region of the dental arch. The prevalence of supernumerary teeth varies from $0.1 \%$ to $3.8 \%$ and is more frequently common in the permanent dentition than in the deciduous dentition and is seen more in maxilla often than in the mandible. ${ }^{5}$

The exact etiology of the supernumerary teeth is not completely understood, but several theories have been suggested for their occurrence. The most commonly accepted theory is the "dental lamina hyperactivity theory" which suggested that supernumerary teeth are formed as a result of the hyperactivity of the dental lamina. ${ }^{1,2}$ Supernumerary teeth are named according to their location within the dental arch and are categorized into four groups: mesiodens, paramolars, parapremolars distomolars and into two distinct types based on morphology: eumorphic (supplemental) or dysmorphic (rudimentary). The crowns of supplemental teeth resemble that of normal teeth. The rudimentary supernumerary teeth could present different anatomic configurations, including conical, tuberculate (several cusps), infundibulum (deep central grooves) and odontoma-like (when it cannot be included in any

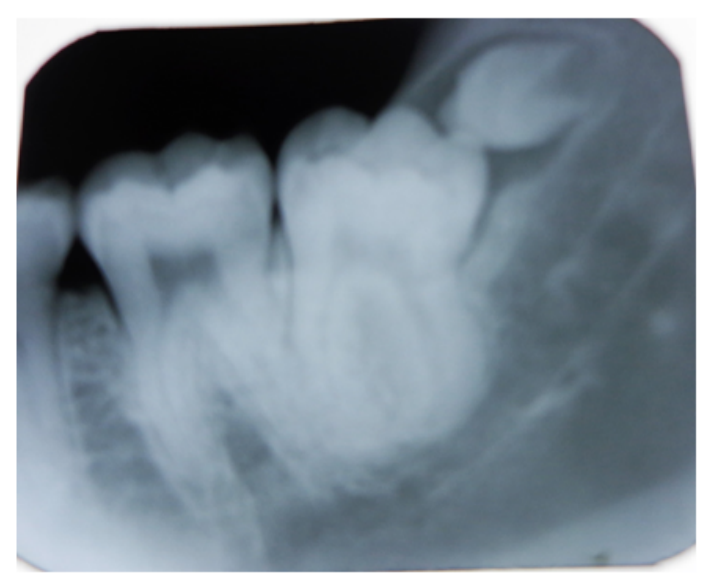

Figure 1A periapical radiograph demonstrating a slightly distoangular, partially impacted left mandibular third molar with an associated horizontally oriented distomolar in the region of the distolingual cuspal tip 
other morphological category)., ${ }^{2,7-9}$ Celikoglu et al. ${ }^{10}$ reported that $70 \%$ of erupted supernumerary teeth were supplemental while $30 \%$ were rudimentary. Generally, multiple supernumerary teeth were supplemental while $30 \%$ were rudimentary. Generally, multiple supernumerary teeth are associated with several developmental anomalies or syndromes such as cleft lip and palate, cleidocranial dysostosis, trichorhinophalangeal syndrome, gardner's syndrome, ehrler-danlos syndrome, down syndrome, cherubism and fabry-anderson syndrome. The presence of a family history of hyperdontia could be indicative of genetics in the possible etiology of supernumerary teeth. ${ }^{5,7-9,11}$

Distomolars are often rudimentary in shape and either conical or tuberculate. They are, in most, case impacted, and extraction may be indicated if there is an associated pathology or the tooth may be retained for frequent observation. This paper reports an unusual case of mandibular distomolar.

\section{Case Report}

A 23-year-old female patient presented to our clinic with a four-day history of pain on the lower right posterior quadrant. The pain was spontaneous, throbbing in nature and radiated to the ear. It was aggravated by chewing and relieved by analgesics. The family and medical histories were non-contributory. The intraoral examination revealed partially erupted mandibular with tender and inflamed overlying operculum on the crown of the mandibular left third molar. There was associated lymphadenitis of the left submandibular lymph nodes. Patient's temperature was not elevated and oral hygiene was good. Figure 1 initial radiographic examination included a periapical radiograph of

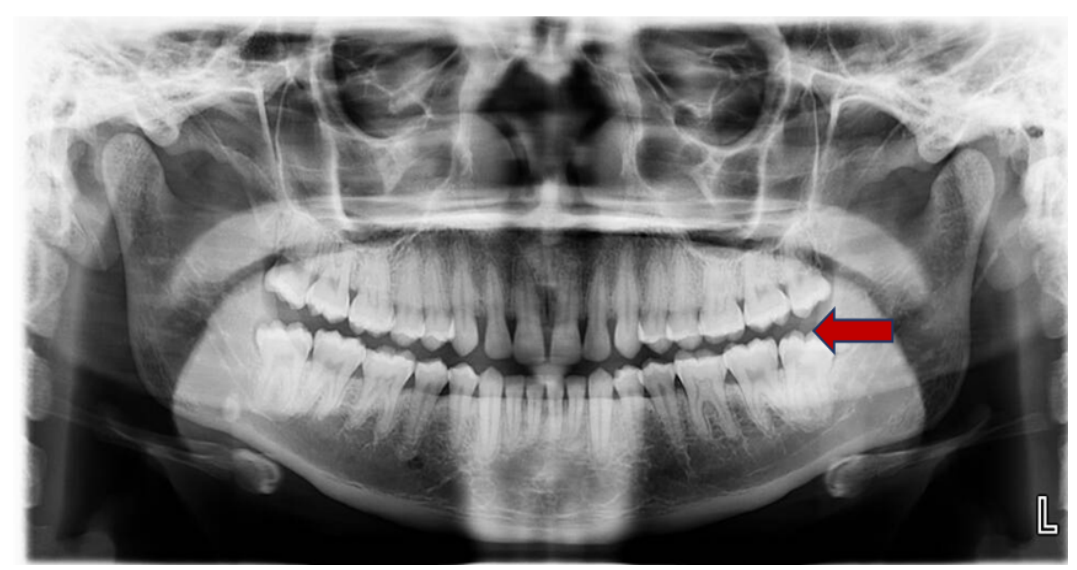

Figure 1 A panoramic radiograph portraying bilateral partially impacted mandibular third molars and a distomolar posterior to the mandibular left third molar (arrow) mandibular third molar which revealed a left mandibular third molar at same occlusal level as the adjacent second molar. However, there is a slight distal inclination of the posterior segment of the tooth and the crown is impacted against a ledge of bone preventing its full eruption. There was an incidental finding of a distomolar distal to the left mandibular third molar. Figure 2 a panoramic radiograph was requested to review the four quadrants of the maxillomandibular regions. The mandibular right third molar was also impacted. However, distomolar was limited to the mandibular left molar region.

The treatment plan included extraction of the impacted mandibular left third molar and the supernumerary tooth. The patient decided to delay the treatment.

\section{Discussion}

Supernumerary teeth, also called hyperdontia, can be seen in any region of the dental arch but appears to be more frequent in the maxilla than mandible with a reported prevalence of $0.2 \%-0.3 \% .^{1-3,6}$ Although the etiology of supernumerary teeth are not clearly understood, a number of theories have been postulated to described the origin of supernumerary teeth; these include phylogenetic (atavistic) theory, dichotomy theory and the dental lamina hyperactivity theory. The phylogenetic (atavistic) theory suggests that the development of supernumerary teeth is as a result of phylogenetic reversion to an extinct primitive dentition with three pair of incisors. The dichotomy theory suggests that tooth separate into two equal or differentsize parts which could give rise to two equal teeth or one normal and one dysmorphic tooth respectively. This is one theory that has been rejected. The dental lamina hyperactivity theory presupposes that supernumerary teeth are formed as a result local, independent, conditioned hyperactivity of dental lamina. However, the role of complex interaction among a variety of environmental and genetic have also been considered. . $^{1,2,7-10}$

A report of the genetic modulation published by Juuri et al. ${ }^{12}$ suggests that mutation of some genes have been identify as a cause of supernumerary teeth formation. According to Juuri et al. ${ }^{12}$ SOX2 expression in human dental lamina suggests that a dormant capacity for sequential tooth formation exist in human and SOX2 may have inhibitory role in successional tooth formation. ${ }^{12}$ 
cases, the diagnosis of supernumerary teeth is often an incidental finding upon radiographic examination. ${ }^{1,6,7}$ A panoramic radiograph demonstrates the entire jaws and is a useful modality for the evaluation of patients presenting with supernumerary teeth because they are well tolerated due to their non-invasive profile and provide information of pathology within the oral cavity and maxilla. ${ }^{13}$ However, using 2D radiographic techniques, such as periapical and panoramic radiographs, has disadvantages in determining the precise three-dimensional location of the teeth in relationship to neighboring structure and adjacent teeth. Cone Beam Computed Tomography (CBCT) provides an exact location of the tooth because it permits multiplanar reformatting and $3 \mathrm{D}$ rendering..$^{14}$ This enables accurate evaluation of the intraosseous location and morphology of the impacted supernumerary teeth.

Fourths molas are often asymptomatic and impacted. Impacted fourth molars may be associated with a number of complications such as pain, periodontal diseases, root resorption, delayed eruption, odontoma, cystic formation, neuralgias of trigeminal nerve, fascial space infection and Temporomandibular Joint (TMJ) disorders. ${ }^{1-3,6,8}$ The ratio of erupted to unerupted distomolars is reported as $1: 5 ., 11$

The treatment of supernumerary teeth remains controversial. Extraction may be indicated in symptomatic cases while frequent observation is indicated in asymptomatic cases. Treatment depends on the type and location of the supernumerary teeth and its potential adverse effect on adjacent hard and soft tissue structures. ${ }^{2}$

\section{Conclusion}

Distomolars are a rare clinical finding and are often impacted and located in the maxilla. Most distomolars are incidental findings during routine radiographic examination and since they are asymptomatic, do not require treatment. Where treatment is indicated, extraction is often considered.

\section{Conflict of Interest}

The authors expressed no conflicts of interest with this study.

\section{References}

1. Zouloumis L, Parrisi A, Anagnostou C, et al. Supernumerary molars: fourth or distomolars. Clinical study and review of the literature. Balk J Stom 2010;13: 167-170.

2. Constantine A, Fonseca GM, Cantin M. Bilateral mandibular fourth molars: a case report. Rev Stomatol Chir Maxillofac Chir Orale 2015;116: 315-316.

3. Rahnama M, Szyszkowska M, Pulawska M, et al. A rare case of retained fourth molar teeth in maxilla and mandible. Case report Curr Issues Pharm Med Sci 2014;27: 118-120.

4. Shahzad KM, Roth LE. Prevalence and management of fourth molars: a retrospective study and literature review. J Oral Maxillofac Surg 2012;70: 273-275.

5. Kaya E, Güngör K, Demirel O, et al. Prevalence and characteristics of non-syndromic distomolar:a retrospective study. J Investig \& Clin Dentist 2015;6: 282-285.

6. Kaya MI, Aktan AM, Ay S, et al. Characteristics of 351 supernumerary molar teeth in Turkish population. Med Oral Pathol Oral Cir Bucal 2012;17: e396-e399.

7. Yadav RK, Rao J, Yadav L, et al. Non-syndromic multiple supernumerary teeth in permanent dentition: a rare phenomenon. BMJ Case Rep 2013: 1-2.

8. Pippi R. Odontomas and supernumerary teeth: is there a common origin?. Int J Med Sci 2014;11: 1282-1285.

9. Arandi NZ. Distomolars: an overview and 3 case reports. Dent Oral Craniofac Res 2017;4: 1-3.

10. Celikoglu M, Kamak H, Oktay H. Prevalence and characteristics of supernumerary teeth in a nonsyndromic Turkish population. Associated pathologies and proposed treatment. Med Oral Patol Oral Cir Bucal 2010;15: e576-e578.

11. Harel-Raviv M, Eckler M, Raviv E, et al. Fourth molars: a clinical study. Oral Surgery 1996: 379-381.

12. Juuri E, Balic A. The biology of underlying abnormalities of teeth number in humans. J Dent Res 2017;96: 1253.

13. Dang HQ, Constantine S, Anderson PJ. The prevalence of dental anomalies in an Australian population. Aust Dent J 2017;62: 161-163.

14. Mossaz J, Kloukos D, Pandis N, et al. Morphologic characteristics, location and associated complications of maxillary and mandibular supernumerary teeth as evaluated using cone beam computed tomography. Eur J Orthod 2014;36: 717

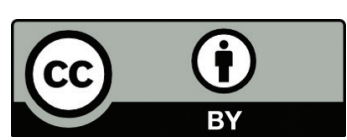

This work is licensed under a Creative Commons Attribution 